\title{
Erosive investigation of various erosion models for vibro cleaner developed based on ultrasonic technique using COMSOL multiphysics
}

\author{
Vipulkumar Rokad*, Divyang H. Pandya \\ Department of Mechanical Engineering, Kadi Sarva Vishwavidhyalaya, Gandhinagar, Gujarat, INDIA \\ *Corresponding Author: e-mail: vipulrokad@gmail.com, Tel +91-9979112126 \\ ORCID iD: http:/orcid.org/0000-0001-6241-1460 (Rokad), https://orcid.org/ 0000-0002-7994-2898 (Pandya)
}

\begin{abstract}
The ability of ultrasound to produce highly controlled erosion phenomenon was investigated and various erosion models have been compared by considering various parameters. In cleaning industry, Vibro Cleaner (VC) has been used to remove contaminations from the surface of metal components. This process is most preferable to out of reach or critical surface of the objects. The novelty of this research is to compare various erosion models and to identify appropriate model for ultrasonic cleaning application to get meaningful results of metal removal rate. The computational model of Vibro Cleaner has been developed using pressure acoustic transient in COMSOL Multiphysics software. Acoustic and Computational Fluid Dynamics (CFD) modules have been coupled together to investigate erosion rate. In acoustic approach, acoustic pressure and sound pressure level have been studied by means of piezoelectric transducer through tank wall transience. In CFD approach, Bubbly fluid flow has been applied to get turbulence in acoustic streaming. Also, particle tracing has been coupled to understand the particle trajectories and motion of fluid flow. Erosion terms are also introduced at a surface of metal parts which need to be clean. The Erosion rate has been evaluated by using cavitation erosion phenomenon in which cavitation bubbles strike and implode over the metal surface and clean the dirt, dust, oil and other contaminations. Various Erosion models like Finnie, E/CRC, Oka and Det Norske Veritas (DNV) have been studied and results have been compared to identify appropriate erosion model towards the ultrasonic cleaning application by considering $28 \mathrm{kHz}$ frequency and PZT-4 piezoelectric transducer. Comparative study leads to conclude that the Finnie erosion model have given stringent results as compare to other erosion model.
\end{abstract}

Keywords: Pressure acoustic transient, Erosion rate, Piezoelectric transducer, Cavitation erosion effect, COMSOL Multiphysics.

DOI: http://dx.doi.org/10.4314/ijest.v13i2.4

Cite this article as:

Rokad V., Pandya D.H. 2021. Erosive investigation of various erosion models for vibro cleaner developed based on ultrasonic technique using COMSOL multiphysics. International Journal of Engineering, Science and Technology, Vol. 13, No. 2, pp. 33-41. doi: 10.4314/ijest.v13i2.4

Received: March 20, 2021; Accepted: April 5, 2021; Final acceptance in revised form: May 7, 2021

\section{Introduction}

The propagation of ultrasonic waves in a liquid media may lead to acoustic cavitation. It is defined by American Society for Testing and Materials (ASTM) standard as the formation and subsequent collapse of cavitation bubbles withing liquid media. Vibro Cleaner (VC) works based on ultra sound effects and used for ultrasonic cleaning process. Ultrasonic cleaning process operates on the principle of pressure waves and cavitation effects. Piezoelectric transducer, mounted on the surface of tank, has been used to convert electric energy into mechanical sound waves which strikes on the surface of the tank wall and reacts as 
pressure waves itself in the liquid media by means of cavitation effect. Cavitation bubbles, generated by cavitation effect, burst over the surface of the component and clean the surface by erosion phenomenon (Krella and Zakrzewska, 2018). The erosion can be affected by a number of factors including impact angle, particle flow, particle size and shape. It is also affected by fluid properties, flow condition and material comprising the impact surface (Tangsopa and Thongsri, 2020; Rokad and Pandya, 2021).

In General, Vibro Cleaner is a closed vessel which has been developed to clean the contaminated surfaces of various components like hard disk drives, automobiles, dental and surgical instruments, tools and many other industrial equipment. By varying different frequencies between $20-400 \mathrm{kHz}$ through different frequency transducer (Tangsopha et al., 2017), various components have been cleaned with appropriate solvent. It is one of the safe and eco-friendly method of cleaning towards the environment too. The results of cleanliness are uncertain. To avoid repeated cleaning and part damage, simulation has been introduced to study the ultrasonic cavitation erosion (Tangsopa and Thongsri, 2019; Duran and Teke, 2019). For simulation, COMSOL Multiphysics has been used. Pressure Acoustic Transient module of COMSOL Multiphysics gives strengthen results for studying sound pressure level and pressure waves. By coupling CFD module, Fluid flow and particle tracing, with acoustic module, various cavitation erosion phenomenon have been studied. Based on literature review, Finnie, Det Norkse Veritas (DNV), Oka and E/CNC are the erosion models that have been selected for ultrasonic cleaning (Rokad and Pandya, 2021). Comparative studies of selected erosion model have carried out at common simulation platform of COMSOL (COMSOL User's Guide, 2017).

\section{Technical Background}

\subsection{Mechanism of Cavitation Erosion}

The erosion phenomenon is widely studied and several theories have been introduced in a manner to describe the mechanism to remove material from the surface of object by particle impact. Cavitation erosion produces enormous energy to clean the surface in ultrasonic cleaning. Bubbles are created by sound waves which have been generated by piezoelectric transducer. Transducer is attached outside the tank wall and tank wall reacts as a transition between liquid media and transducer. When power is applied, Rapid vibration of transducer surface creates lowest and highest-pressure phase change in liquid media which generates millions of tiny bubbles called "Cavitation bubbles". These empty spaced bubbles strike and explode over the surface of the object as fast as it generates (Krella and Zakrzewska, 2018). These gives enormous cleaning power to the surface of part to clean the contaminants from the surface of object is known as "Cavitation effect". Erosion is the process of surface deterioration and surface material loss due to generation of vacuum pockets inside the liquid. Contaminant material has been eroded by the effect of cavitation from the surface of parts so it is also known as "Cavitation Erosion effect". This constant implosion produces tremendous vacuum energy in the form of heat and pressure that gives great cleaning power near the surface of parts to clean the contaminants which is known as "cavitation effect" (Ibanez et al., 2020).

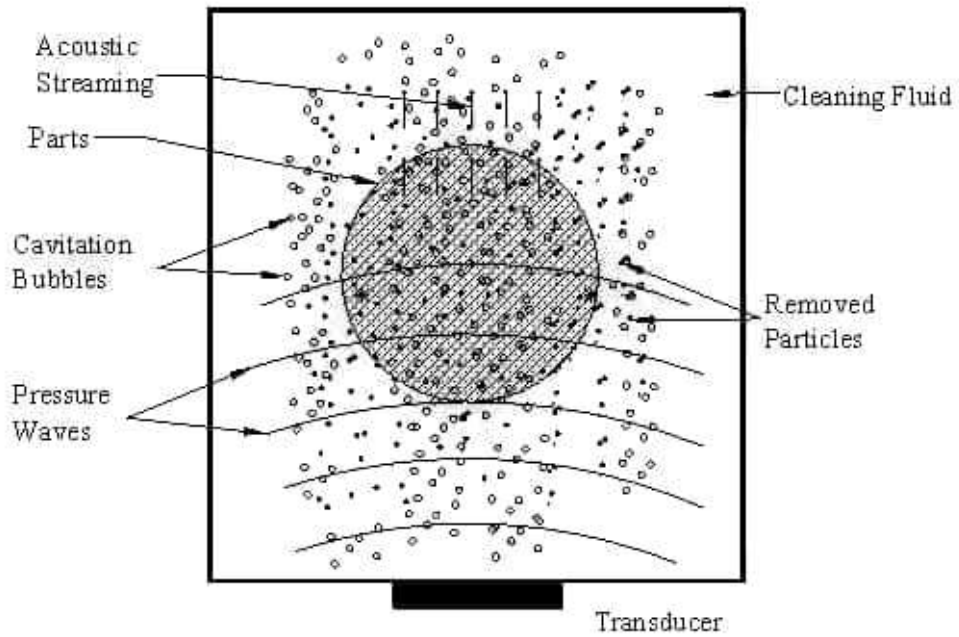

Figure 1. Working Principle of cavitation erosion for Ultrasonic Cleaning

\subsection{Simulation Background and Equation:}

The Simulation has been carried out using COMSOL Multiphysics by coupling Acoustic module and CFD module.

Acoustic Approach: For computational model, Pressure acoustic transient module has been used with frequency domain (Lais et al., 2018). Piezoelectric transducer is directly attached to the outer tank wall which converts electrical energy into sound pressure level. By means of tank wall transience, mechanical sound waves converted into pressure waves in liquid media which creates millions of tiny cavitation bubbles. These bubbles strike over the surface of components and clean the surface. In boundary conditions, all tank walls reacted as external boundaries which have been defined as sound hard boundaries where 
internal boundaries defined as sound soft boundaries. Spherical wave radiation has been chosen for wave radiation due to cavitation effect. Stainless steel has been used as tank material because of its elastic sustainability and anti-corrosive properties. Roller terminology creates the wave transmission from piezoelectric material to liquid through SS tank wall in solid mechanics - Linear elastic. Acoustic approach is the combination of pressure acoustic transient, solid mechanics - linear elastic and electrostatic terms. In electrostatics, PZT-4 piezoelectric transducer (De Angelis et al., 2016) has been used for processing because it works on high mechanical factor and preload. Also, it has low die-electric losses, so it is most preferable for ultrasonic cleaning application. $230 \mathrm{~V}$ power has been applied for transducer operating (Virot et al., 2010; Zhong, 2015; Rokad and Pandya, 2021).

$$
\begin{aligned}
& \nabla \cdot\left(\frac{-1}{\rho_{c}}\left(\nabla \cdot p_{t}-q_{d}\right)\right)-\frac{K_{e q \cdot}^{2} \cdot p_{t}}{\rho_{c}}=Q_{m} \\
& -\rho \omega^{2} u=\nabla \cdot s+F_{v} e^{i \phi},-i k_{z}=\lambda \\
& S=S_{a d}+C: \in_{e l}+\left(-\frac{1}{3} \operatorname{trace}\left(C: \in_{e l}\right)-\rho_{w}\right) l, \in_{e l}=\in-\epsilon_{\text {inel }} \\
& -\rho \omega^{2} u=\nabla \cdot(F . S .)^{T}+F_{v} e^{i \phi}, F=I+\nabla u,-i k_{z}=\lambda \\
& S=S_{0}+J_{i} F_{\text {inel }}^{-1}\left(C: \in_{e l}\right) J_{i} F_{\text {inel }}^{-T}-E \cdot e,+\in_{e l}=\frac{1}{2}\left(F_{e l}^{T} F_{e l}-1\right), F_{e l}=F F_{\text {inel }}^{-1} \\
& D=D_{r}+e \cdot \varepsilon_{e l}+\in_{0 v a c}\left(\in_{r s}+J C^{-1}-1\right) \cdot E, J=\operatorname{det}(F), C=F^{T} \cdot F
\end{aligned}
$$

Computational Fluid Dynamics (CFD) Approach: CFD approach is the combination of fluid flow and particle tracing of fluid flow terms. Cavitation effect creates bubbles due to phase difference of lower and higher pressure. Because of this bubbly flow has been used to generate turbulence in the moving fluid. Bubbly flow k- $\varepsilon$ model gives more appropriate results than other models. Also, Particle tracing module is used to trace the trajectories of particles in the presence of an external field. Fluid based particle tracing helps to investigate the motion of fluid particle in liquid media. The forces like drag and acoustophoretic radiation force have been predefined and fluid flow has been computed with it to get suitable results. Various erosion criteria have been applied on the surface of the parts which need to be cleaned (EI-Behery et al., 2010; Arabnejad et al., 2015).

$$
\begin{aligned}
& \phi_{1} \rho_{1}\left(u_{1 .} \nabla\right) u_{1 .}=\nabla \cdot[-\rho 2 I+K]+\phi_{1} \rho_{1} g+F \\
& \frac{d\left(m_{v} V\right)}{d t}=F_{t} \\
& F_{D}=\frac{1}{\tau_{p} S} m_{p} M\left(u^{\prime}-V\right) \\
& F_{r a d}=-2 \pi r_{p}^{2}\left[\frac{1}{3} k_{S} \operatorname{Re}\left(f_{0}^{f l} \rho * \nabla \rho\right)-\frac{1}{2} \rho \operatorname{Re}\left(f_{1}^{f l} u^{*} \cdot \nabla u\right)\right] \\
& \Delta m_{i}=\frac{c_{i} \rho m_{p} V_{i}^{2}}{4 H_{V}\left(1+m_{p} r_{p}^{2} / l_{p}\right)} F\left(\alpha_{i}\right) \\
& F\left(\alpha_{i}\right)=\left\{\begin{array}{c}
\cos ^{2} \alpha_{i} \\
\frac{2}{p}\left[\sin ^{2}\left(2 \alpha_{i}\right)-\frac{2}{p} \sin ^{2} \alpha_{i}\right]
\end{array}{\tan \alpha_{i} \leq \frac{P}{2}}_{\tan \alpha_{\mathrm{i}} \succ \frac{P}{2}}\right.
\end{aligned}
$$




$$
P=\frac{K}{1+m_{p} r_{p}^{2} / I_{p}}
$$

\subsection{Erosion Models}

Erosive wear of metal surface is a difficult process to understand and investigation. It depends on many mechanical and physical parameters. There are many aspects of erosion models available for the study of erosion rate considering various different conditions of fluid flow.

Finnie Erosion Model: Ian Finnie is the first person to propose a wear model. The erosion considers erosion rate by solid particle over the metal surface in fluid stream which depends on the fluid flow condition and mechanism of material removal. It looks like the cutting edge of a tool moves over the surface of metal to create deformation and removal of material which is done by the particles of fluid flow. Considering Q, as the volume of material removed by grains of mass $\mathrm{M}$ with a velocity V and $\alpha$ as the angle at which the particle strikes the surface (Yang et al., 2020).

$$
\begin{gathered}
E_{M j}=\frac{C_{j} \rho m_{p} f_{r e l} V_{i}^{2}}{4 H_{v}\left(1+\frac{m_{p} r_{p}^{2}}{l_{p}}\right)} F\left(\alpha_{i}\right) \\
F\left(\alpha_{i}\right)= \begin{cases}\cos ^{2} \alpha_{i} & \tan \alpha_{\mathrm{i}} \succ \frac{P}{2} \\
\frac{2}{p}\left[\sin \left(2 \alpha_{i}\right)-\frac{2}{p} \sin ^{2} \alpha_{i}\right]_{\operatorname{an} \alpha_{\mathrm{i}} \leq \frac{P}{2}}\end{cases}
\end{gathered}
$$

E/CRC Erosion Model: This model is developed by Erosion Corrosion Research Centre. For this model various parameters have been considered like $\mathrm{C}$ is the constant and equal to $2.17 \mathrm{c} 10^{-7}, \mathrm{BH}$ is the Brinell hardness, $\mathrm{V}_{\mathrm{p}}$ is the particle impact velocity and $F_{s}$ is the particle shape coefficient and its equal to 1 for sharp angular, 0.53 for semi rounded and 0.2 for fully rounded, $\theta$ is the particle impact angle (Yang et al., 2020).

$$
E_{M, i}=C f_{r e l} F_{S}(B H)^{-0.59}\left(\frac{V}{V_{r e f}}\right)^{n} F\left(\alpha_{i}\right)
$$

Oka Erosion Model: The idea behind this model is that the impact angle adopted which is the ratio of erosion damage at arbitrary angle to the erosion damage at normal angle (Y. I. Oka, al. 2005) (Yang et al., 2020).

$$
\begin{gathered}
E_{M, i}\left(\alpha_{i}\right)=f_{r e l}\left(\sin \alpha_{i}\right)^{n_{1}}\left[1+\left(\frac{H_{v}}{1[G P a]}\right)\left(1-\sin \alpha_{i}\right]^{n_{2}} E_{M, i}\left(\frac{\pi}{2}\right)\right. \\
E_{M, i}\left(\frac{\pi}{2}\right)=K\left(\left(\frac{H_{v}}{1[G P a]}\right)^{k_{1}}\left(\frac{v}{V_{r e f}}\right)^{k_{2}}\left(\frac{d_{p}}{d_{r e f}}\right)^{k_{3}}\right)
\end{gathered}
$$

DNV Erosion Model: Det Norske Veritas (DNV) developed as an erosion model based on numerous experimental data and numerical predicted results. Here, ER (erosion rate) is defined as the wall mass loss per unit area and per unit time. $F(\alpha)$ is the impact angle function, $\mathrm{A}$ is a constant, with default value of $2.0 \times 10^{-9}$ for steel, $\mathrm{n}$ is a constant exponent, with default value of 2.6. The DNV correlation does not explicitly depend on particle diameter (Yang et al., 2020). 


$$
\begin{gathered}
E_{M, i}=K f_{r e l}\left(\frac{V}{1\left[\frac{m}{s}\right]}\right) F\left(\alpha_{i}\right) \\
F\left(\alpha_{i}\right)=\sum_{k=1}^{8}(-1)^{k+1} A_{k} \alpha_{i}^{k}
\end{gathered}
$$

\section{Methodology}

In this section, Research Methodology and related parameters have been discussed to develop Vibro Cleaner to improve performance.

\subsection{Input Parameters for Vibro Cleaner and other parts:}

The cylindrical shaped ultrasonic tank has been developed for the investigation. The size of tank is $125 \mathrm{~mm}$ radius $\mathrm{x} 200$ $\mathrm{mm}$ height with $2 \mathrm{~mm}$ tick wall. For the making tank, $2 \mathrm{~mm}$ SS sheet material has been used. It contains approximately 10 litters volume of water. Stainless steel material has been chosen due to good elasticity and durability. The PZT-4 Piezoelectric transducer has been used as a source of ultrasonic wave which has high mechanical preload and low die-electric losses. The transducer is capable to generate acoustic waves at different frequencies like $28 \mathrm{kHz}$ with $230 \mathrm{~V}$. For the cleaning of object, Aluminum sphere has been used to study the process of ultrasonic cleaning (Tangsopa and Thongsri, 2020).

Table 1. Values of Certain properties of materials.

\begin{tabular}{|l|c|c|}
\hline Properties & Stainless Steel & Aluminum \\
\hline Density & $7850 \mathrm{~kg} / \mathrm{m}^{3}$ & $2700 \mathrm{~kg} / \mathrm{m}^{3}$ \\
\hline Young's Modulus & $20 \times 10^{10} \mathrm{~Pa}$ & $7.0 \times 10^{10} \mathrm{~Pa}$ \\
\hline Poisson's Ratio & 0.30 & 0.30 \\
\hline Bulk Modulus & $11.5 \times 10^{10} \mathrm{~Pa}$ & $5.1 \times 10^{10} \mathrm{~Pa}$ \\
\hline Shear Modulus & $7.69 \times 10^{10} \mathrm{~Pa}$ & $2.6 \times 10^{10} \mathrm{~Pa}$ \\
\hline
\end{tabular}

\subsection{Computational Model and Simulation:}

Computer-aided design (CAD) model has been developed by using COMSOL Multiphysics software. COMSOL Multiphysics contains many modules which can be coupled to gather to get meaningful results. The model has been developed based on 2D axisymmetric method. Here, two modules like Acoustic and CFD have been coupled to get efficient results of the study. Acoustic module includes terms like pressure acoustic transient, solid mechanics - linear elastic, electrostatics (Lais et al., 2018) where CFD module includes turbulence fluid flow in the form of bubbly flow k- $\varepsilon$ model and particle tracing of fluid flow which contains erosion modules. Particle tracing module shows the movement of fluid particles and particle engagement with parts to get the erosion phenomenon for cleaning. PZT-4 piezoelectric transducer is attached at the bottom of the tank wall which converts electrical energy into sound pressure level. Due to this sound pressure level, tank wall vibrates repeatedly which transmits sound pressure level into pressure waves in the form of cavitation bubbles. These cavitation bubbles strike and implode over the surface of part which need to be clean. The surface of the part has been cleaned due to continue bombarding of tiny bubbles (Chine et al., 2010; Zamankhan et al., 2014). 
(a)

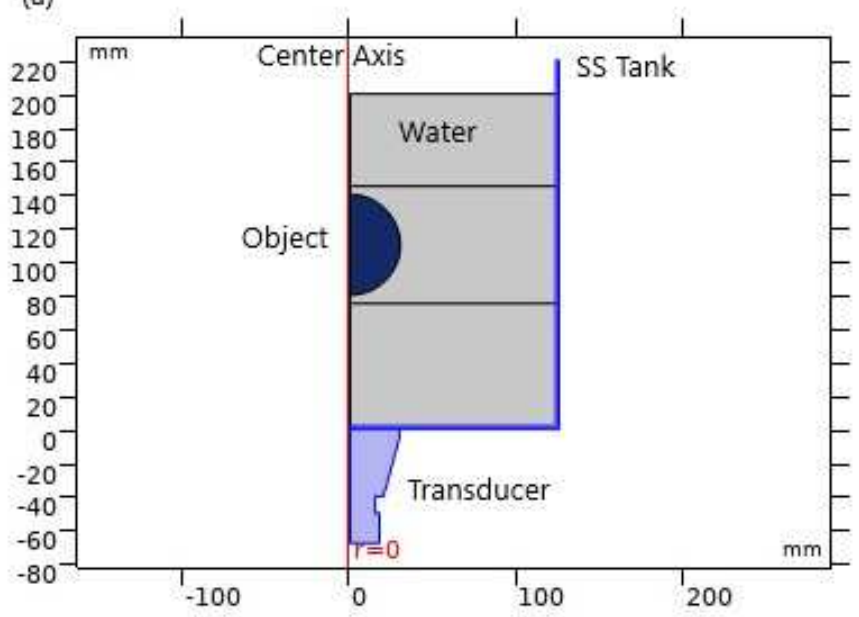

(b)

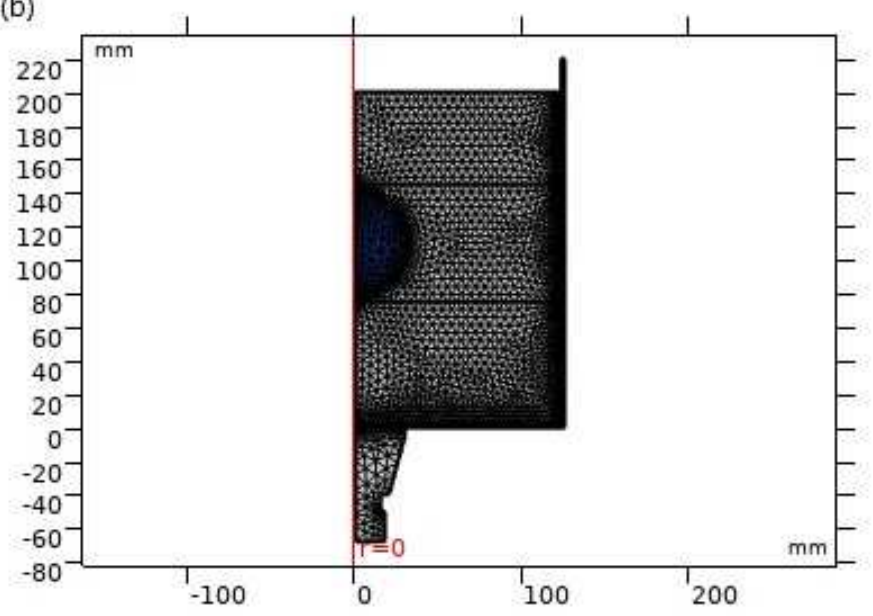

Figure 2. (a) 2D Axisymmetric Geometric Model; (b) Mesh Model

In simulation, Meshing is one of the most important to get flow full result specially for wave generation. Here, Extra-fine meshing has been chosen which is of the COMSOL default method. It consists maximum element size 3 and minimum element size 0.1 . Also, the growth rate is 1.7 with curvature factor 0.8. Resolution of the narrow region has been taken 0.3 . Refer fig. 2(b) for meshing of geometric model.

For simulation, COMSOL Multiphysics version 5.3a has been used. The frequency domain has been used for the study of acoustic pressure and sound pressure level because it is specially designed to study the responses of sound pressure level in pressure acoustic transient module. SS tank and aluminum have been set as solid domains and water as liquid domain. In electrostatic condition, piezoelectric transducer has been used to transform piezoelectric energy into acoustic properties. Here, to get the acoustic streaming in the form of turbulence, bubbly fluid flow has been used with stationary solver which gives the motion of fluid on appropriate ways. Particle tracing module has been applied to study the motion of fluid particles with fluid flow using time depended solver. The movement of particles has been done in the environment of drag force, acoustophoretic radiation force. Various erosion models have been applied on the surface of the cleaning part by considering various erosive parameters. Here, Finnie, E/CRC, Oka and DNV erosion models have been applied for comparison of applicability of stringent result of metal erosion rate.

\section{Results and Discussion}

In this study, Computational model has been developed based of 2D axisymmetric method using COMSOL Multiphysics which has enough capabilities to get more stringent result by coupling two or more modules. PZT-4 piezoelectric transducer has been used to transmit electric properties into acoustic properties in the environment of wall transience in fluid media. Adequate results of acoustic pressure, sound pressure level and von mises stresses have been achieved.
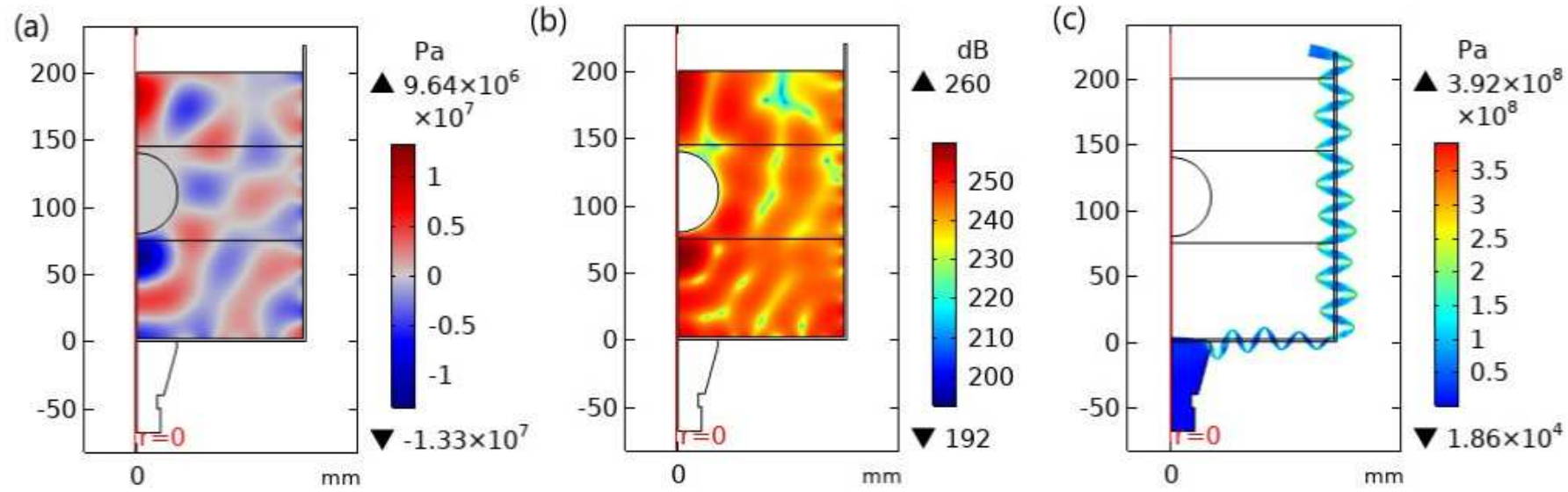

Figure 3. (a) Acoustic Pressure Pa; (b) Sound Pressure Level, dB; (c) Von Mises Stresses, Pa 
(a)

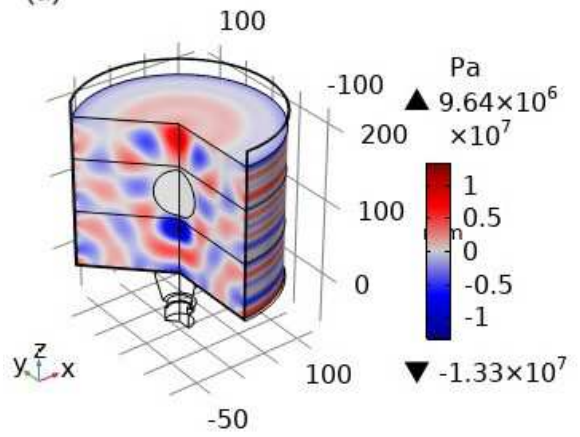

(b)

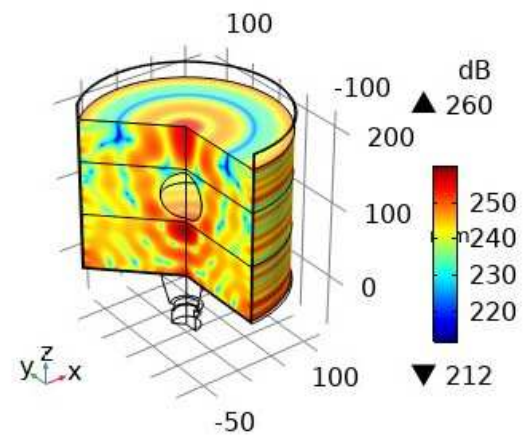

(c)

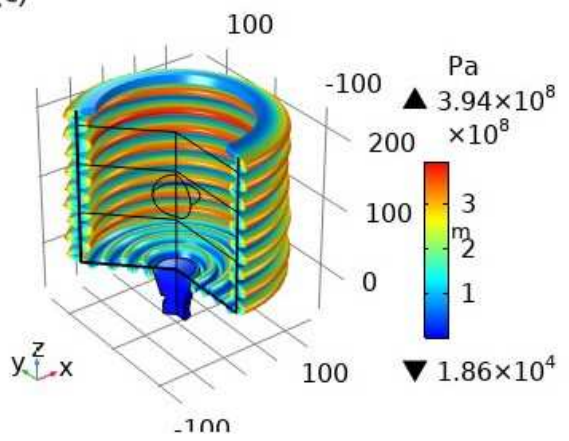

Figure 4. (a) Acoustic Pressure Pa; (b) Sound Pressure Level, dB; (c) Von Mises Stresses, Pa (Axisymmetric 3D)

Result shows, at a frequency of $28 \mathrm{kHz}$, the acoustic pressure and sound pressure level are $9.64 \times 10^{6} \mathrm{~Pa}$ and $260 \mathrm{~dB}$ respectively where in previous work it was $101 \mathrm{kPa}$ maximum. Axisymmetric 2D and 3D views have been shown for more clarity. Also, Tank is made of SS material which is more elastic and durable. It sustains high von mises stresses like $3.92 \mathrm{x}$ $10^{8} \mathrm{~Pa}$.

(a)

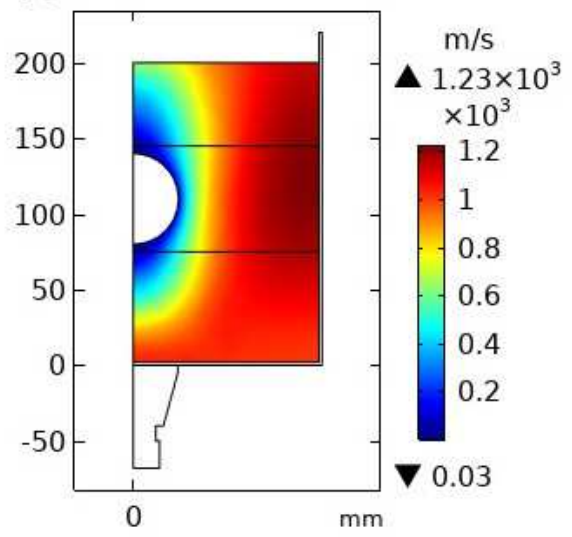

(b)

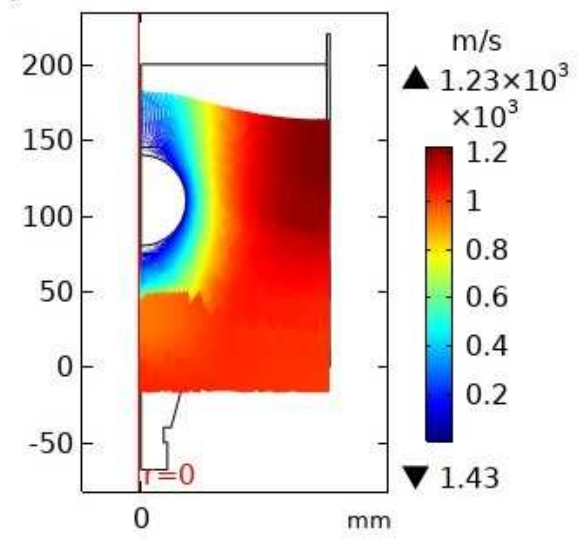

(c)

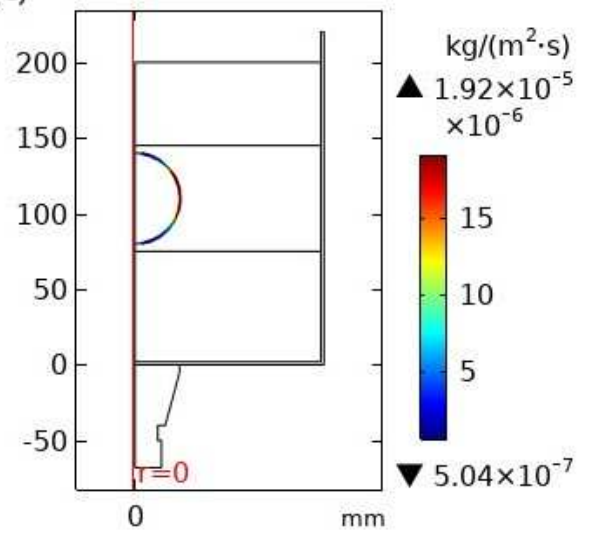

Figure 5. (a) Velocity Magnitude, m/s; (b) Particle Trajectories; (c) Erosion Rate - Finnie Model, kg/(m² s)

Fluid flow and particle tracing have been applied to study the motion of particle and erosion rate of various theories. To study the erosion rate, bubbly fluid flow has been chosen to get the cavitation bubble streaming and motion of particles with respect to surface of cleaning parts.

(a)

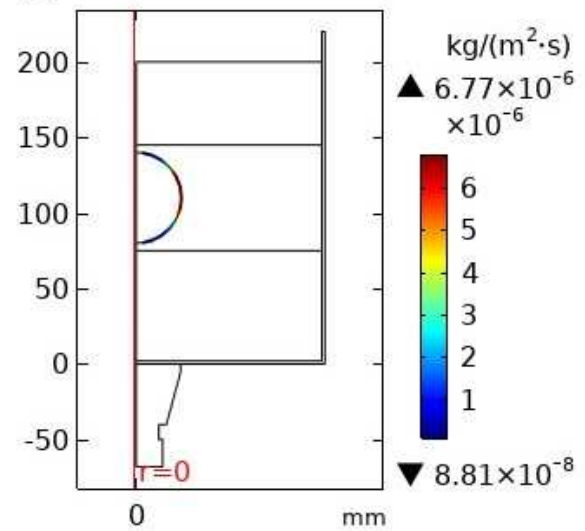

(b)

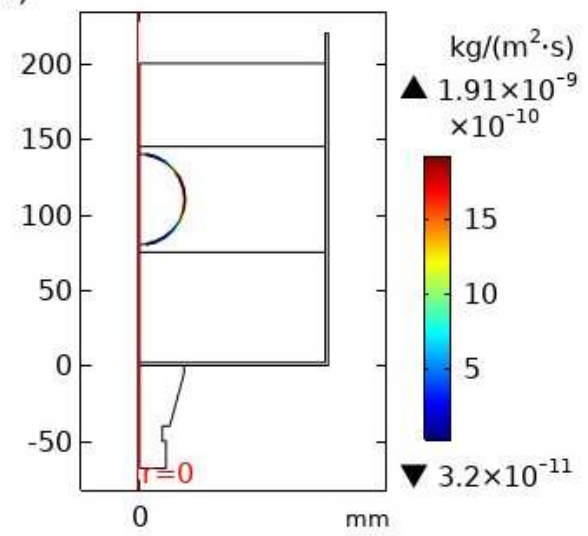

(c)

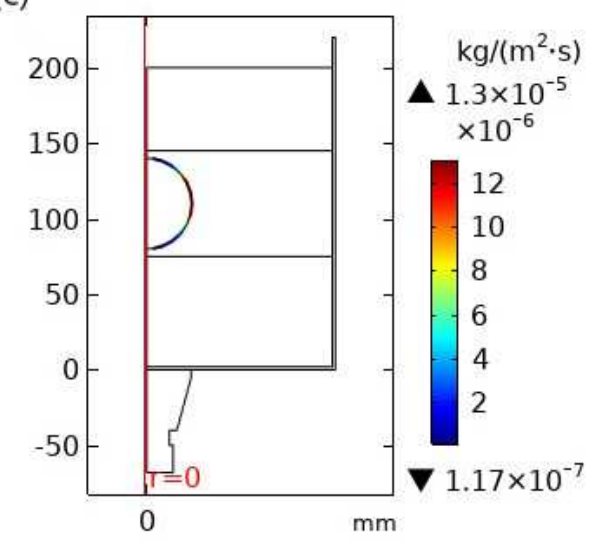

Figure 6. (a) Erosion Rate - E/CRC, $\mathrm{kg} /\left(\mathrm{m}^{2} \mathrm{~s}\right)$; (b) Erosion Rate - Oka, $\mathrm{kg} /\left(\mathrm{m}^{2} \mathrm{~s}\right)$; (c) Erosion Rate - DNV, $\mathrm{kg} /\left(\mathrm{m}^{2} \mathrm{~s}\right)$

All erosion models have been used considering many variables like fluid flow, particle diameter, particle density, flow 
velocity, properties of material which need to be clean and liquid media. All erosion models have been studied in same environment of ultrasonic cleaning application and comparable results have been achieved. The Finnie erosion model gives $1.92 \times 10^{-5} \mathrm{~kg} /\left(\mathrm{m}^{2} \mathrm{~s}\right)$ by considering model parameters like fraction of particle cutting as 0.1 , ratio of normal and tangential force as 2. In E/CRC erosion model, Parameters like model coefficient, particle shape coefficient and model exponent are $2.17 \times 10^{-7}, 0.2$ and 2.41 respectively have been considered and $6.77 \times 10^{-6} \mathrm{~kg} /\left(\mathrm{m}^{2} \mathrm{~s}\right)$ erosion rate achieved. The Oka erosion model gives $1.91 \times 10^{-9} \mathrm{~kg} /\left(\mathrm{m}^{2} \mathrm{~s}\right)$ erosion rate by considering various factors like particle size, velocity and many more. Same as DNV erosion model gives $1.17 \times 10^{-5} \mathrm{~kg} /\left(\mathrm{m}^{2} \mathrm{~s}\right)$ erosion rate with $2 \times 10^{-9}$ model coefficient and 2.6 model exponent.

\section{Conclusions}

Cavitation erosion has given meaningful exposure in the field of ultrasonic cleaning applications. In present work, various erosion models have been studied and compared on common simulation platform of COMSOL, which have capabilities to couple effects of acoustics \& computational fluid dynamics. Finnie, E/CRC, Oka and DNV are the erosion models have been evaluated with considering factors like particle size, fluid flow properties, material surface hardness and density along with velocity of cleaning media. All erosion models have compared at $28 \mathrm{kHz}$ input frequency and aluminum object to be clean in the acoustic field. Simulated results of COMSOL have concluded that Finnie erosion model have recognized as significant erosion model with highest erosion rate of $1.92 \times 10^{-5} \mathrm{~kg} /\left(\mathrm{m}^{2} \mathrm{~s}\right)$. Outcome of present research is to understand the effect of various parameters of erosion model and enhance applicability of ultrasonic cleaning as value added services at jewelers or FMCG store apart from its industrial applications.

\section{References}

Abouel-Kasem A. and Ahmed S.M., 2012, Bubble structures between two walls in ultrasonic cavitation erosion, Journal of Tribology, Vol. 134, pp. 021702-1 to 9. https://doi.org/10.1115/1.4005217

Arabnejad H., Mansouri A., Shirazi S.A. and McLaury B.S., 2015. Evaluation of solid particle erosion equation and models for oil and gas industry application, Society of Petroleum Engineering Conference, SPE-174987-MS. https://doi.org/10.2118/174987MS

Chine B. and Monno M., 2010. A model of gas bubble growth by Comsol Multiphysics, The COMSOL Conference 2010 Paris.

De Angelis D.A. and Schulze G.W., 2016, Performance of PZT8 versus PZT4 piezoceramic materials in ultrasonic transducers, $44^{\text {th }}$ Annual Symposium of the Ultrasonic Industry Association, Washington, DC, USA. https://doi.org/10.1016/j.phpro.2016.12.014

Duran F, Teke M., 2019. Design and implementation of an intelligent ultrasonic cleaning device, Intelligent Automation and Soft Computing, Vol. 25, No. 3, pp. 441-449. doi:10.31209/2018.11006161

El-Behery S.M., Hamed M.H., Ibrahim K.A. and EI-Kadi M.A., 2010. CFD evaluation of solid particles erosion in curved ducts, Journal of Fluid Engineering, Vol. 132, pp. 071303-1 to 10. https://doi.org/10.1115/1.4001968

Ejeh C.J., Boah E.A., Akhabue G.P., and Onyekperem C.C., 2020, Computational fluid dynamic analysis for investigating the influence of pipe curvature on erosion rate prediction during crude oil production, Experimental and Computational Multiphase Flow, Vol. 2, No. 4, pp. 255-272. https://doi.org/10.1007/s42757-019-0055-5

Ibanez I., Zeqiri B., Hodnett M. and Frota M.N., 2020. Cavitation-erosion measurements on engineering materials, Engineering Science and Technology an International Journal, Vol. 23, pp. 1486-1498. https://doi.org/10.1016/j.jestch.2020.06.001

Introduction to COMSOL Multiphysics - User's Guide, 2017, Version 5.3a.

Jafari A. and Hattani R.A., 2018. Investigation of parameters influencing erosion wear using DEM, Friction, Vol. 8, No. 1, pp. 136-150. https://doi.org/10.1007/s40544-018-0252-4

Krella A.K. and Zakrzewska D.E., 2018. Cavitation erosion-Phenomenon and test rigs, Advances in Materials Science, Vol. 18, No. 2, p. 56. DOI: 10.1515/adms-2017-0028

Lais H., Lowe P.S., Gan T.-H. and Wrobel L.C., 2018. Numerical modeling of acoustic pressure fields to optimize the ultrasonic cleaning technique for cylinders, Ultrasonics - Sonochemistry, Vol. 45, pp. 7-16. https://doi.org/10.1016/j.ultsonch.2018.02.045

Oka Y.I., Okamura K. and Yoshida T., 2005. Practical estimation of erosion damage caused by solid particle impact part 1: Effects of impact parameters on a predictive equation, Wear, Vol. 259, pp. 95-101. https://doi.org/10.1016/j.wear.2005.01.039

Rokad V. and Pandya D.H., 2021. Development of 3D improved acoustic transient model for vibro cleaner using COMSOL Multiphysics, Materials Today Proceedings, Vol. 44, No. 1, pp. 732-736. https://doi.org/10.1016/j.matpr.2020.10.635

Tangsopha W., Thongsri J., Bussayaporn W., 2017. Ultrasonic cleaning and ways to improve the efficiency. in Proc. 5th International Electrical Conference (IEECON2017), 8-10 May, Pattaya, Thailand, pp. 121-124

Tangsopa W. and Thongsri J., 2019. Development of an industrial ultrasonic cleaning tank based on harmonic response analysis, Ultrasonics, Vol. 91, pp. 68-76. https://doi.org/10.1016/j.ultras.2018.07.013

Tangsopa W. and Thongsri J., 2020. A novel ultrasonic cleaning tank development by harmonic response analysis and computational fluid dynamics, Metals, Vol. 10, No. 3, pp. 1-18. https://doi.org/10.3390/met10030335

Virot M., Chave T., Nikitenko S.I., and Shchukin D.G., 2010, Acoustic cavitation at the water - glass interface, Journal of 
Physical Chemistry-C, Vol. 114, pp. 13083-13091. https://doi.org/10.1021/jp1046276

Yang S., Zhang M., Xingang and Wang H., 2020. Numerical simulation of fluid carrying pollutant particles erosion in elbow pipe is carried out by COMSOL, IOP Publishing: International Conference on Electrical Automation and Mechanical Engineering, 1626, 012109.

Zamankhan P. 2014. Simulation of cavitation water flows, Hindawi - Mathematical Problems in Engineering, Vol. 2015. https://doi.org/10.1155/2015/872573

Zhong L., 2015. COMSOL Multiphysics simulation of ultrasonic energy in cleaning tanks, COMSOL Conference.

\section{Biographical notes}

Vipulkumar Rokad is a research scholar in department of mechanical at Kadi Sarva Vishwavidhyalay, Gandhinagar with Machine design specialization, working on Acoustic and Vibration studies of Ultrasonic cleaning application. His areas of interests are the Ultrasonic technology, machine design and production and hard metal and anti-wear technology. He has worked as the Assistant Professor in Mechanical Engineering Department at Kalol Institute of Technology and Research centre, Kalol, India, and served the college in several other administrative positions. He received his B.E. degree in Mechanical Engineering from Jadatguru Datattray College of technology, Indore, India, and M.E. degree in Mechanical engineering with a specialization in Machine Design from Kalol Institute of Technology and Research Centre, Kalol, Gujarat, India.

Prof. (Dr.) Divyang H. Pandya did His PhD from IIT Roorkee, India. Presently he is working as a professor and HOD in the same department. His area of interest includes Vibration, condition monitoring, signal processing, expert system and machine design etc. He has more than 65 publications in referred journals and international conferences. 